\title{
The Effects of $\mathrm{SO}_{2}$ Contamination, Brine Salinity,
}

\author{
Pressure, and Temperature on Dynamic Contact Angles
}

and Interfacial Tension of Supercritical $\mathrm{CO}_{2} /$ Brine/Quartz

\author{
Systems
}

Soheil Saraji*, Mohammad Piri, and Lamia Goual

Department of Chemical and Petroleum Engineering, University of Wyoming

1000 E. University Avenue, Laramie, WY 82071-2000, USA

KEYWORDS

Interfacial tension, Contact angle, Contact angle hysteresis, Supercritical $\mathrm{CO}_{2}, \mathrm{SO}_{2}, \mathrm{Brine}$ salinity, Quartz, ADSA-NA 


\section{ABSTRACT}

The successful implementation of geologic $\mathrm{CO}_{2}$ sequestration schemes in deep saline aquifers requires storage sites with minimum risk of $\mathrm{CO}_{2}$ leakage through the caprock and maximum storage capacity in the reservoir rock. Some of the essential parameters that affect the effectiveness of a storage scheme are the density of $\mathrm{CO}_{2}$, the interfacial tension between $\mathrm{CO}_{2}$ rich and aqueous phases, and the wettability of reservoir rock and caprock in contact with these fluids at reservoir conditions [1]. In this study, densities, interfacial tensions, and dynamic contact angles of $\mathrm{CO}_{2} /$ brine/quartz systems at high temperatures and pressures were simultaneously measured using the Axisymmetric Drop Shape Analysis with no-Apex (ADSANA) method. Measurements were performed at pressures (2000-4000 psig), temperatures (50$\left.100{ }^{\circ} \mathrm{C}\right)$, and brine salinities $(0.2$ to $5 \mathrm{M})$ relevant to carbon sequestration in deep saline aquifers. These experimental conditions had not been investigated in the past. Additionally, the effect of $\mathrm{SO}_{2}$ as a co-contaminant (0-6 wt.\%) was investigated on these parameters for the first time. Contact angle hysteresis was also examined and the possible implications of the results on different $\mathrm{CO}_{2}$ trapping mechanisms were discussed. 


\section{INTRODUCTION}

The growing demand for energy and the abscence of reliable alternatives to fossil fuels are causing an increase in carbon dioxide $\left(\mathrm{CO}_{2}\right)$ production as a by-product of energy generation. In order to avoid the adverse effects of carbon emissions to the climate, the current viable solution is to reduce $\mathrm{CO}_{2}$ emmisions by improving the energy efficiency and implement effective carbon capture, utilization, and storage schemes. $\mathrm{CO}_{2}$ has been injected into petroleum reservoirs for Enhanced Oil Recovery (EOR) since 1970s [2]. Although this scheme has been successful, limited amounts of carbon are currently stored with this approach [2]. The increase in the amount of $\mathrm{CO}_{2}$ that will have to be stored due to prospectively tighter regulations on carbon emmisions, mandates finding new storage sites. Saline aquifers are promising future sinks of carbon dioxide with potentially high storage capacities. These sinks have been under investigation since 1990s and there are several successful demonstrations and full-field projects currently active for storage of carbon dioxide in deep saline aquifers across the world [3].

Figure 1 shows the most likely ranges of pressure and temperature at which saline aquifers are

found underground. This graph is created considering the earth's surface temperature ranging from 15 to $25{ }^{\circ} \mathrm{C}$, the geothermal gradient between 20 to $30{ }^{\circ} \mathrm{C} / \mathrm{km}$, and hydrostatic pressure gradient of about $1500 \mathrm{psi} / \mathrm{km}$. Although there are possible cases of cold reservoirs, for example in the Arctic [4], or extremely hot reservoirs [5], it is expected that this range to be valid for most of the saline aquifers. The phase diagram of carbon dioxide is also superimposed on the same graph, demonstrating that $\mathrm{CO}_{2}$ is most likely to be in supercritical state in underground aquifers (shaded area in Figure 1). For the purpose of carbon sequestration, it is desirable to find an aquifer having a pressure and temperature where $\mathrm{CO}_{2}$ has the highest density so that a maximum mass of carbon dioxide can be stored per unit volume. For pressures higher than 4000 psig (or 
reservoirs deeper than about $3 \mathrm{~km}$ ), the density change of $\mathrm{CO}_{2}$ phase becomes minimal and the cost of compression and injection of $\mathrm{CO}_{2}$ becomes uneconomical [4]. Also, in agreement with the above argument, the reported $\mathrm{CO}_{2}$ injection depths for sixteen active carbon dioxide storage operations in saline aquifers are between 0.7 and $3 \mathrm{~km}$ [3]. Therefore, we selected pressure and temperature ranges that were not explored in the past and can be considered more practical for carbon sequestration in deep saline aquifers (filled red circle symboles in Figure 1)..

The salinity of the sedimentary basins that have been used for $\mathrm{CO}_{2}$ storage varies considerably from 7,000 ppm to the maximum salt solubilty in water which is about $360,000 \mathrm{ppm}$ [3]. However in the United States, the EPA regulations do not permit any $\mathrm{CO}_{2}$ injection in aquifers with total dissolved solids (TDS) of less than 10,000 ppm [6]. Brine salinity is an important parameter that affects the solubility of $\mathrm{CO}_{2}$, interfacial tension (IFT) between the fluids, wettability of the reservoir rock and caprock, and hence the storage capacity and security of carbon storage in aquifers [1]. The effect of brine salinity on wettability or contact angle (CA) of quartz and glass surfaces in $\mathrm{CO}_{2}$ /brine systems have been recently studied by different research groups [5], [7]-[15]. While some studies did not observe any significant effect of brine salinity on wettability of the substrate [8], [11]-[15], others reported a clear decrease in water-wetness of quartz surface with an increase in brine salinity [5], [9], [10], [16]. In this study, a broad range of brine salinity $(0.2-5 \mathrm{M} \mathrm{NaCl})$, compatible with EPA regulations and currently active $\mathrm{CO}_{2}$ sequestration projects, was investigated.

A report by Miller and Van Atten [17] listed the annual emissions of about 700 power plants across North America. They have reported 2400 million tons of $\mathrm{CO}_{2}$ emission into the atmosphere per year from these power plants. Other gases such as Sulfur Dioxide or $\mathrm{SO}_{2}(11.5$ million tons per year) and Nitrogen Oxides or $\mathrm{NO}_{\mathrm{x}}$ (4.5 million tons per year) are also present in 
the emission stream. These gases (co-cotaminants) can be co-injected with $\mathrm{CO}_{2}$ for geological storage, and thereby avoiding extra cost of separation process. However, there are very limited experimental data on the impact of these chemical species on the geological storage of $\mathrm{CO}_{2}$ and its security. Furthermore, the wettability state of reservoir minerals and caprock in the presence of, for instance, $\mathrm{SO}_{2}$ as a co-contaminant has not been studied in the past. There are, currently, very few experimental data exist on the interfacial tension and contact angle of $\mathrm{H}_{2} \mathrm{~S}+\mathrm{CO}_{2}$ mixture/brine/rock systems at reservoir conditions. Shah et al. [18] measured the interfacial tension between pure $\mathrm{H}_{2} \mathrm{~S}$ and 30 mole $\% \mathrm{H}_{2} \mathrm{~S}+\mathrm{CO}_{2}$ mixture in contact with water. They reported a considerable reduction in IFT with increase in $\mathrm{H}_{2} \mathrm{~S}$ concentration. Broseta et al. [5] compared the contact angles of $\mathrm{CO}_{2}$ /brine and $\mathrm{H}_{2} \mathrm{~S}$ /brine on mica and quartz surfaces and did not observe any significant difference between the contact angles of these two fluid systems. For the first time, the effect of $\mathrm{SO}_{2}$ as a co-contaminant in supercritical $\mathrm{CO}_{2}\left(\mathrm{sc}-\mathrm{CO}_{2}\right)$ on IFT and dynamic contant angles of a representative system for geological storage of carbon dioxide were examined in this study.

An experimental setup [19] was used to simultaneously measure densities, interfacial tensions, and dynamic contact angles of $\mathrm{CO}_{2} /$ brine/quartz systems. Measurements were performed at pressures (2000-4000 psig), temperatures $\left(50-100{ }^{\circ} \mathrm{C}\right)$, and brine salinities $(0.2$ to $5 \mathrm{M})$ relevant to carbon sequestration in deep saline aquifers (Figure 1). The effect of $\mathrm{SO}_{2}$ as a co-contaminant in supercritical $\mathrm{CO}_{2}(0-6$ wt.\%) on fluid densities, interfacial tensions and dynamic contact angles was also investigated. The contact angle hysteresis was calculated and its correlation with pressure, temperature, brine salinity, and $\mathrm{SO}_{2}$ content was examined.

In this paper, we first present a brief description of the experimental setup and measurement procedures. The effects of temperature, pressure, brine salinity, and $\mathrm{SO}_{2}$ concentration on the 
above-mentioned properties are examined next. Lastly, possible implications of the observed trends on the geological sequestration of carbon dioxide are discussed.

\section{MATERIALS AND METHODS}

\subsection{Materials}

Materials include: isopropyl alcohol (HPLC grade, Sigma-Aldrich), sulfuric acid (95-98\%, ACS grade, Sigma-Aldrich), SuperSmooth ${ }^{\text {TM }}$ quartz slides (SPI supplies) with surface roughness smaller than $0.5 \mathrm{~nm}$, NOCROMIX (Godax Laboratories, Inc.), nitrogen (instrumental grade, Praxair, Inc.), $\mathrm{CO}_{2}$ (instrumental grade, Praxair, Inc.), and anhydrous $\mathrm{SO}_{2}$ (instrumental grade, Praxair, Inc.). The $\mathrm{CO}_{2}$ gas cylinders were equipped with a Syphon tube for liquid withdrawal and the distilled water was freshly obtained from an in-house all-glass water distiller.

\subsection{Experimental Setup}

An IFT/CA apparatus [19] was utilized to perform measurements at high pressures (up to 4000 psig) and temperatures (up to $100^{\circ} \mathrm{C}$ ). The experimental setup, shown in Figure 2, can handle highly corrosive fluids since all wetted parts are made out of Hastelloy C-276, polyether ether ketone (PEEK), Sapphire glass, and AFLAS O-rings. In this system, a fluid equilibration module enabled the pre-equilibration between partially miscible phases before measurements. A temperature-controlling module provided accurate and stable temperatures inside the measurement cell $\left( \pm 0.05{ }^{\circ} \mathrm{C}\right)$. A dual-cylinder pulse-free Quizix pump allowed transfer of the equilibrated phases from the equilibration module into the measurement cell at constant pressure. It also provided low and stable flow rates for injection/retraction of $\mathrm{CO}_{2}$ bubble during the measurements. An Anton Paar DMA HPM density meter, made out of Hastelloy C-276, was used to measure the densities of equilibrated fluids at elevated pressures and temperatures. 
Before IFT and CA measurements for $\mathrm{CO}_{2}$ /brine/quartz system, the experimental procedures and measurement techniques were carefully validated with the experimental data available in the literature. The details of the experimental setup and also the validation procedure can be found in Saraji et al. [19].

In this study, captive bubble configuration was used for IFT/CA measurements. Images of bubbles were captured through a microscope with fully apochromatically corrected lenses attached to a high-resolution digital camera with a standard resolution of $2048 \times 1536$ (3 megapixels). The images were analyzed using a well-established technique, i.e. axisymmetric drop shape analysis with no apex (ADSA-NA) [20], to simultaneously calculate the interfacial tension and dynamic contact angle of $\mathrm{CO}_{2}$ bubbles in brine. In this technique, the profile of a bubble captured in an image is extracted by an edge detection method. The program then fits a theoretical Laplacian curve to the experimental profile extracted from the image with the assumption of an axisymmetric bubble shape. Afterwards, the value of IFT is determined from the best match between these two profiles. It then uses the final optimum theoretical profile to find the contact angle at the solid surface level. By convention, the contact angle is measured through the denser fluid (i.e. aqueous phase). It has been shown that contact angles can be measured with an accuracy of $0.2^{\circ}$ with this method [20]. Further details about this technique can be found elsewhere [20].

\subsection{Substrate Preparation}

The quartz substrates were prepared with a specific procedure to ensure clean surfaces (i.e. strongly water-wet). A 10\% NOCROMIX in sulfuric acid solution was used as the cleaning agent and the substrates were then boiled in distilled water to ensure acid-free hydroxylated surfaces. The substrates were handled from their edges with clean tweezers to avoid surface 
contamination throughout the preparation stage. A few minutes before each test, the substrates were removed from the distilled water bath and dried by absorbing the bulk water remaining on them with a filter paper (at the edges) and then blow-drying with ultrahigh-purity (UHP) nitrogen. Afterwards, the quartz substrate was mounted on a PEEK crystal holder and then installed inside the measurement cell.

\subsection{Experimental Procedure}

The fluids were pre-equilibrated before measurements in the equilibration cell for about $10-12 \mathrm{~h}$ to produce equilibrated $\mathrm{CO}_{2}$-rich and aqueous phases at the desired pressure $(\mathrm{P})$ and temperature (T). Prior to IFT/CA measurements, the densities of equilibrated phases were measured at the same $\mathrm{P}$ and $\mathrm{T}$. The measurement cell was pressurized with $\mathrm{CO}_{2}$ and temperature was adjusted to the desired experimental condition. The cell was then filled with the aqueous phase at constant pressure until the solid substrate (quartz) was fully immersed in brine. The fluids and the solid remained inside the measurement cell for about $2 \mathrm{~h}$ before the IFT and CA measurements were performed. A pedestal-shaped needle with $1.37 \mathrm{~mm}$ outer diameter at the tip was selected based on Bond number calculations for a representative system. It was then used for all the measurements in this study. The needle was utilized to form $\mathrm{CO}_{2}$ bubbles beneath the quartz substrate, while the needle tip was kept at 3-4 $\mathrm{mm}$ from the quartz surface. With this configuration, it was possible to conduct measurements on different areas of the same quartz surface by moving the substrate horizontally. Each substrate was used only once to avoid any possible contaminations.

In order to facilitate the detection of the substrate surface during contact angle measurements, the camera was tilted $1-2^{\circ}$ upward with respect to the horizontal line. This approach allowed the mirror image of the bubble on the substrate to be captured in the digital image. A simple 
mathematical criterion was used to determine the cutoff pixel (substrate surface) in all of the images. We first considered a few hundred pixels on the bubble surface (BS) near the contact line together with their mirror image (MI). The substrate surface was defined as the average midpoint between vertically aligned BS and MI pixels. This algorithm was applied on two sides

of the bubble and the two cutoff values were utilized for contact angle measurement. Images of the $\mathrm{CO}_{2}$ bubble were taken repeatedly while the bubble was growing (water receding contact angle) or shrinking it (water advancing contact angle) at intervals of $5 \mathrm{sec}$. The ADSA-NA software was used to calculate both IFT and CA from the same images of the captive bubbles. The primary input parameters required for the calculations were the density difference between the fluid phases, acceleration of gravity, image scales, and the location of the solid surface.

\section{RESULTS AND DISCUSSION}

In order to investigate the effects of pressure $(2000-4000 \mathrm{psig})$, temperature $\left(50-100{ }^{\circ} \mathrm{C}\right)$, brine salinity (0.2-5 M), and $\mathrm{SO}_{2}$ concentration in $\mathrm{CO}_{2}(0-6$ wt.\%) on IFT and CA of sc$\mathrm{CO}_{2} /$ brine/quartz, seventeen separate tests were performed. Table 1 lists the densities of equilibrated phases, interfacial tensions between fluids, as well as water advancing and receding contact angles measured under above-mentioned conditions. All the data presented in this table are the average of 3-5 measurements.

\subsection{Natural wettability of quartz surface}

The effect of surface contamination on contact angle measurements in $\mathrm{CO}_{2} /$ brine/quartz systems was first addressed in a communication between Bikkina [21], [22] and Mahandavan [23]. Later, Saraji et al. [19] pointed out the possibility of contamination as a major source of discrepancy in the reported contact angles for such systems. They proposed an extensive substrate cleaning 
procedure, storage in distilled water before use, and drying the surface with ultrahigh-purity Nitrogen as necessary steps to avoid surface contamination. Most recently, Iglauer et al. [24] investigated the effect of cleaning procedure on contact angle of $\mathrm{CO}_{2} /$ brine on quartz/glass surfaces and concluded that inappropriate cleaning methods could result in artificially high contact angles. They reported relatively low contact angles $\left(0-30^{\circ}\right)$ for clean surfaces, which is consistent with the values reported by Saraji et al. [19]. However, using oxidizing solutions such as Piranha [24] and NOCROMIX in sulfuric acid solution [19] may cause hydroxylation of the quartz surface and hence change its wettability. Therefore, it is important to understand the natural wettability of quartz surface at conditions relevant to carbon sequestration before coming into contact with $\mathrm{CO}_{2}$ phase.

The previous studies on the surface chemistry of silica suggest that the wettability of silica surface is largely determined by the arrangement and distribution of surface groups such as silanol (Si-OH) and siloxane (Si-O-Si) [25], [26]. For instance, a recent molecular dynamics simulation study reported approximately $10^{\circ}$ increase in contact angle by increasing the silanol surface density on quartz from 1.7 to $4.5\left(\mathrm{OH} / \mathrm{nm}^{2}\right)$ [12]. The reason for this behavior is the preferential adsorption of water molecules on hydrophilic silanols rather than hydrophobic siloxanes [25]. Moreover, thermal treatment of silica at very high temperatures $\left(>400{ }^{\circ} \mathrm{C}\right)$ is shown to cause dehydroxylation of its surface, meaning conversion of silanols to siloxanes [26]. For example, Horn et al. [27] reported a relatively high contact angle (i.e. $45^{\circ}$ ) on freshly prepared high-purity silica surface by the melting method (the melting point of silica is around $\left.1600{ }^{\circ} \mathrm{C}\right)$. In contrast, soaking silica in water is believed to result in rehydroxylation of silica surface [26]. This process is exceedingly slow at $25^{\circ} \mathrm{C}$, and it is recommended to heat silica in water at $95{ }^{\circ} \mathrm{C}$ for several hours to rehydroxylate the surface [25]. This is also in accord with the 
reported water contact angles on hydrophilic quartz/glass surfaces $\left(<10^{\circ}\right)$ measured by different methods such as Wilhelmy plate [28], capillary rise [29], and sessile drop [30].

Therefore, the surface of quartz minerals in contact with aquifer at subsurface conditions, in extended geological time scales, is expected to be hydroxylated. Although one can argue that the quartz grains in reservoir rocks are partly covered by omnipresent clays, the clean pure hydroxylated quartz surface (strongly water-wet) provides a practical baseline for fundamental research on fluid-mineral interactions during geological sequestration of carbon dioxide.

\subsection{Effects of pressure and temperature}

The pressure and temperature ranges used in this study are $2000-4000$ psig and $50-100{ }^{\circ} \mathrm{C}$, respectively, as shown in Figure 1. Experiments were performed at nine different conditions, all with a brine salinity of $1 \mathrm{M}$. Because brine is largely incompressible in the pressure and temperature range of these experiments, its density was not affected by pressure change; although it slightly decreased when temperature was increased (Figure 3a). On the other hand, supercritical carbon dioxide $\left(\mathrm{sc}-\mathrm{CO}_{2}\right)$ is a compressible fluid and its density increased with increasing pressure and decreased with increasing temperature (Figure 3a). The interfacial tension between equilibrated $\mathrm{CO}_{2}$-rich and aqeous phases at various temperatures and pressures are plotted in Figure 3b. As shown in this figure, variations in pressure did not have a significant effect on the IFT, but an increase in temperature slightly reduced the IFT values. Figure 4a shows the experimental $\mathrm{CO}_{2}$ solubility data in $1 \mathrm{M}$ brine and its variations with $\mathrm{P}$ and $\mathrm{T}$ reported in Koschel et al. [31]. The relative insensitivity of IFT to $\mathrm{P}$ and $\mathrm{T}$ in the supercritical region of $\mathrm{CO}_{2}$ may stem from the fact that the solubility of $\mathrm{CO}_{2}$ in brine $(1 \mathrm{M})$ does not drastically change in the $\mathrm{P}$ and $\mathrm{T}$ ranges studied here. Similar to the IFT data, the dynamic contact angles also did 
not change drastically with $\mathrm{P}$ and $\mathrm{T}$ (Figure $3 \mathrm{c}$ ). There was only a slight increase in the water angles and contact angle hysteresis $(\Delta \theta)$ by the increase in pressure (the last column of Table 1 and Figure 3d). However, due to the lack of enough temperature overlap in the prtesented data a general trend cannot be deducted.

\subsection{Effect of brine salinity}

In a recent publication by Michael et al. [3], the authors summarized the operational conditions for sixteen active sequestration sites worldwide with brine salinities ranging from 7,000 to 340,000 ppm. Therefore, three different salinities were chosen for our studies that are in the range of 0.2 to $5 \mathrm{M} \mathrm{NaCl}(\sim 11,500$ to $300,000 \mathrm{ppm})$ to cover the spectrum of brine salinities observed in underground aquifers. All the measurements in this section were performed at 3000 psig.

The densities of $\mathrm{CO}_{2}$-rich and aqeous phases at various $\mathrm{NaCl}$ concentrations are plotted in Figure 5a. As expected, the density of $\mathrm{CO}_{2}$ was insensitive to the changes in salt concentration, however brines with higher ionic strength had larger densities. Figure $5 \mathrm{~b}$ depicts the variations of IFT with ionic strength. There was a significant increase in IFT with increase in ionic strength. For example, IFT between equilibrated sc- $\mathrm{CO}_{2}$ and brine at 3000 psig and $60{ }^{\circ} \mathrm{C}$ increased from 26 to $39 \mathrm{mN} / \mathrm{m}$ by changing the ionic strength from 0.2 to $5 \mathrm{M}$. This behavior is partly due to the decrease in $\mathrm{CO}_{2}$ solubility in brine with higher salinities, as shown in Figure 4b, and partly because of hydration of ions that leads to an ion-free layer at the water interface [32].

Figure $5 \mathrm{c}$ depicts the water receding and advancing contact angles of the $\mathrm{CO}_{2} /$ brine/quartz system. There was a consistent increase in both dynamic contact angles with the increase in ionic strength. The observed trend is consistent with the reported data in several studies [5], [7], [9], 
[10]. Furthermore, the hysteresis in contact angle was much larger at higher salinities (Figure 5d). For instance, $\Delta \theta$ increased from $6^{\circ}$ to $22^{\circ}$ with the increase in brine ionic strength from 0.2 to $5 \mathrm{M}$ at $80^{\circ} \mathrm{C}$.

\subsection{Effect of $\mathrm{SO}_{2}$ contaminant}

Based on a report by Miller and Van Atten [17], the $\mathrm{SO}_{2} / \mathrm{CO}_{2}$ ratio in the emission stream of power plants varies between 0.02 to 8 wt.\% with an average of 0.6 wt. $\%$. Thus, to cover the reported $\mathrm{SO}_{2}$ range, two $\mathrm{CO}_{2}$ mixtures with 1 wt. $\% \mathrm{SO}_{2}$ (Test 16 in Table 1) and 6 wt.\% $\mathrm{SO}_{2}$ (Test 17 in Table 1) content were considered in this study. Pressure (3000 psig), temperature (60 $\left.{ }^{\circ} \mathrm{C}\right)$, and brine salinity $(1 \mathrm{M})$ were kept constant for these experiments.

The densities of equilibrated $\mathrm{CO}_{2}$-rich phase for $\mathrm{SO}_{2}+\mathrm{CO}_{2}$ mixtures were larger than those of equilibrated $\mathrm{CO}_{2}$-rich phase in the absence of $\mathrm{SO}_{2}$ (Figure 6a). This is because $\mathrm{SO}_{2}$ has a higher density than $\mathrm{CO}_{2}$. In spite of this, the densities of aqueous phases were slightly smaller in the presence of $\mathrm{SO}_{2}$. This results in a decreasing trend of $\Delta \rho$ with increasing $\mathrm{SO}_{2}$ concentration (Table 1). Figure $6 \mathrm{~b}$ shows that the interfacial tension between equilibrated phases decreased linearly with increase in the $\mathrm{SO}_{2}$ concentration. There was a significant decrease in IFT (i.e. $40 \%$ ) from $29 \mathrm{mN} / \mathrm{m}$ in the case of pure $\mathrm{CO}_{2}$ to $18 \mathrm{mN} / \mathrm{m}$ in the presence of $6 \mathrm{wt} . \% \mathrm{SO}_{2}$. A recent study [33] on the effect of $\mathrm{SO}_{2}$ and $\mathrm{CO}_{2}$ molecules on the gas/water interface was performed by comparing $\mathrm{OH}$ stretching intensities at the interfacial water spectrum. This study showed a clear difference between the interactions of these two molecules with water [33]. The authors observed that a weakly bounded surface complex was formed between $\mathrm{SO}_{2}$ and interfacial water molecules, which affected the molecular structure at the interface. However, no specific surface-bound species were observed in the case of $\mathrm{CO}_{2}$. The presence of this weakly 
bounded surface complex between $\mathrm{SO}_{2}$ and water molecules at the supercritical fluid/liquid interface could be the main contributor for the considerable decrease in IFT values. Similar effects on the IFT of $\mathrm{CO}_{2}$ /brine in the presence of another acid gas (i.e. $\mathrm{H}_{2} \mathrm{~S}$ ) have also been reported [18]. The IFT between $\mathrm{H}_{2} \mathrm{~S}+\mathrm{CO}_{2}$ mixtures and brine under conditions comparable to our experiments dropped from $32 \mathrm{mN} / \mathrm{m}$ for pure $\mathrm{CO}_{2}$ to $26 \mathrm{mN} / \mathrm{m}$ with 30 mole $\% \mathrm{H}_{2} \mathrm{~S}$ and 7.5 $\mathrm{mN} / \mathrm{m}$ with pure $\mathrm{H}_{2} \mathrm{~S}$.

The dynamic contact angles and hysteresis for $\mathrm{SO}_{2}+\mathrm{CO}_{2}$ /brine/quartz system are shown in Figures $6 \mathrm{c}$ and $6 \mathrm{~d}$. We have not observed any significant change in water receding/advancing contact angles and $\mathrm{CA}$ hysteresis by increasing $\mathrm{SO}_{2}$ concentration. This is comparable with the work of Broseta et al. [5] who did not observe any major change in the wettability of quartz when switching from $\mathrm{CO}_{2}$ to $\mathrm{H}_{2} \mathrm{~S}$.

\subsection{Potential implications for $\mathrm{CO}_{2}$ storage}

The main trapping mechanisms of $\mathrm{sc}-\mathrm{CO}_{2}$ in a saline aquifer include: structural/stratigraphic, capillary, solubility, and mineral trappings. The capacity of an aquifer to safely hold $\mathrm{CO}_{2}$ underground as free gas (structural trapping) depends on the threshold capillary pressure of the caprock $\left(\mathrm{Pc}_{\mathrm{th}}\right)$. Based on the Young-Laplace equation (i.e., $P_{C}=\frac{2 . I F T \cdot \cos (C A)}{r}$, r: characteristic radius of pores), $\mathrm{Pc}_{\mathrm{th}}$ is in turn determined by the interfacial tension between $\mathrm{CO}_{2}$-rich and aqueous phases and water receding contact angle $\left(\mathrm{CO}_{2}\right.$ displacing water $)$ [7]. A higher threshold pressure promotes the safe storage of carbon and increases the storage capacity of the aquifer. Also, the water advancing contact angle affects the amount of $\mathrm{CO}_{2}$ that can be trapped as the immobile phase during water imbibition in the reservoir (capillary trapping). In water-wet systems, the lower water advancing contact angles translate to larger volumes of trapped $\mathrm{CO}_{2}$ 
phase. Another critical parameter of the system is the density of $\mathrm{CO}_{2}$ in the reservoir. At higher $\mathrm{CO}_{2}$ densities, greater mass of carbon can be stored per unit volume of the reservoir rock.

Within the P-T range studied here, the interfacial tension and water receding contact angles of $\mathrm{CO}_{2}$ /brine/quartz systems were only slightly affected by changes in $\mathrm{P}$ and $\mathrm{T}$. Therefore one can expect no significant effect on the threshold capillary pressure of the caprock and the capacity for free gas storage in a saline aquifer. Moreover, the water advancing contact angle slightly increased with increasing the pressure and mildly decreased with increasing the temperature. Hence, no significant change is expected in the capillary trapping of $\mathrm{CO}_{2}$ with depth. On the other hand, the density of $\mathrm{CO}_{2}$ phase is highly sensitive to both $\mathrm{P}$ and $\mathrm{T}$ and rises with depth [4]. Thus the capacity of an aquifer for holding $\mathrm{CO}_{2}$ both as free and trapped phases increases with depth to about 3-4 km. For aquifers deeper than $4 \mathrm{~km}$, the density becomes insensitive to $\mathrm{P}$ and $\mathrm{T}$ and therefore remains fairly constant with depth [4].

The increase in brine salinity caused a considerable increase in IFT and a slight increase in water receding contact angle. Small changes in contact angle can be ignored compared to large changes in IFT. Consequently, the overall effect of brine salinity is an increase in the threshold capillary pressure of caprock, hence improved security of $\mathrm{CO}_{2}$ storage as free gas. Conversely, the water advancing contact angle increased at higher salt concentrations while the density of $\mathrm{CO}_{2}$ phase remained unaffected. Therefore, at higher salinities the amount of capillary trapped $\mathrm{CO}_{2}$ is expected to decrease for a given porous medium (at contant $\mathrm{P}$ and $\mathrm{T}$ ). Also, as mentioned earlier, the solubility of $\mathrm{CO}_{2}$ in brine reduces at higher ionic strengths and hence the capacity of brine to dissolve $\mathrm{CO}_{2}$ declines (solubility trapping). Therefore, the overall capacity of the aquifer with changes in brine salinity depends on the competition between these three trapping mechanisms. 
The presence of $\mathrm{SO}_{2}$ as a co-contaminant in $\mathrm{CO}_{2}$-rich phase resulted in a significant decrease in IFT with brine while it did not affect the water receding/advancing contact angles. As a result, we expect $\mathrm{Pc}_{\text {th }}$ to decrease considerably. Unfortunately, the effect of $\mathrm{SO}_{2}$ on solubility trapping of $\mathrm{CO}_{2}$-rich phace in brine is unkown due to the lack of experimental data. Nevertheless, the results presented here suggest co-injection of $\mathrm{SO}_{2}$ with carbon dioxide at relatively low concentrations may increase the risk of capillary failure of caprocks by reducing the IFT.

\section{CONCLUSIONS}

Densities, interfacial tensions, and dynamic contact angles of equilibrated $\mathrm{CO}_{2}$ and brine on quartz surface were measured at pressure and temperature conditions relevant to deep saline aquifers. The results indicated that pressure and temperature variations, within the range studied, did not significantly affect IFT and CA. Also, contact angle hysteresis was only slightly changed by these parameters. On the other hand, an increase in brine salinity resulted in an increase in IFT, CA, and CA hysteresis. Based on these results, at higher brine salinities greater quantities of $\mathrm{CO}_{2}$ may exist in the aquifer as free and capillary trapped phases. Furthermore, the effect of $\mathrm{SO}_{2}$ as a co-contaminant on densities, IFT, and CA of the system was studied for the first time. While rock wettability was not affected by $\mathrm{SO}_{2}$, the IFT between $\mathrm{CO}_{2}+\mathrm{SO}_{2}$ mixture and brine decreased linearly with increase in the amount of $\mathrm{SO}_{2}$ in the $\mathrm{CO}_{2}$-rich phase. Therefore, the co-injection of $\mathrm{SO}_{2}$ at high concentrations in saline aquifers may increase the risk of gas leakage though the caprock. 


\section{AKNOWLEGEMENTS}

This work was supported by DOE Financial Assistance Agreement DE-FE0004832. The authors also acknowledge the financial support of the School of Energy Resources and the Enhanced Oil Recovery Institute at the University of Wyoming.

\section{REFERENCES}

[1] T. K. Tokunaga and J. Wan, "Capillary pressure and mineral wettability influences on reservoir CO2 capacity," Rev. Mineral. Geochemistry, vol. 77, no. 1, pp. 481-503, Nov. 2013.

[2] P. Tomski, V. Kuuskraa, and M. Moore, "US policy shift to carbon capture, utilization, and storage driven by carbon dioxide enhanced oil recovery," 2013.

[3] K. Michael, a. Golab, V. Shulakova, J. Ennis-King, G. Allinson, S. Sharma, and T. Aiken, "Geological storage of $\mathrm{CO} 2$ in saline aquifers - A review of the experience from existing storage operations," Int. J. Greenh. Gas Control, vol. 4, no. 4, pp. 659-667, Jul. 2010.

[4] S. Bachu, "Screening and ranking of sedimentary basins for sequestration of $\mathrm{CO} 2$ in geological media in response to climate change," Environ. Geol., vol. 44, no. 3, pp. 277289, Jun. 2003.

[5] D. Broseta, N. Tonnet, and V. Shah, "Are rocks still water-wet in the presence of dense CO2 or H2S?," Geofluids, vol. 12, no. 4, pp. 280-294, Nov. 2012.

[6] E. J. Wilson, T. L. Johnson, and D. W. Keith, "Regulating the ultimate sink: managing the risks of geologic CO2 storage.," Environ. Sci. Technol., vol. 37, no. 16, pp. 3476-83, Aug. 2003.

[7] P. Chiquet, D. Broseta, and S. Thibeau, "Wettability alteration of caprock minerals by carbon dioxide," Geofluids, vol. 7, no. 2, pp. 112-122, May 2007.

[8] D. N. Espinoza and J. C. Santamarina, "Water-CO2 -mineral systems: Interfacial tension, contact angle, and diffusion-Implications to CO2 geological storage," Water Resour. Res., vol. 46, no. 7, p. W07537, Jul. 2010.

[9] R. Farokhpoor, B. J. a. Bjørkvik, E. Lindeberg, and O. Torsæter, "Wettability behaviour of CO2 at storage conditions," Int. J. Greenh. Gas Control, vol. 12, pp. 18-25, Jan. 2013. 
[10] J. Jung and J. Wan, "Supercritical CO2 and ionic strength effects on wettability of silica surfaces : equilibrium contact angle measurements," Energy and Fuels, no. 26, pp. 60536059, 2012.

[11] S. Wang, Z. Tao, S. M. Persily, and A. F. Clarens, "CO2 adhesion on hydrated mineral surfaces.," Environ. Sci. Technol., vol. 47, no. 20, pp. 11858-65, Oct. 2013.

[12] J. Mccaughan, S. Iglauer, and F. Bresme, "Molecular dynamics simulation of water/ CO2quartz interfacial properties : application to subsurface gas injection," Energy Procedia, vol. 37, pp. 5387-5402, 2013.

[13] S. Iglauer, M. S. Mathew, and F. Bresme, "Molecular dynamics computations of brine$\mathrm{CO} 2$ interfacial tensions and brine- $\mathrm{CO} 2-$ quartz contact angles and their effects on structural and residual trapping mechanisms in carbon geo-sequestration," J. Colloid Interface Sci., no. 386, pp. 405-414, 2012.

[14] S. Wang, I. M. Edwards, and A. F. Clarens, "Wettability phenomena at the CO2-brinemineral interface: implications for geologic carbon sequestration.," Environ. Sci. Technol., vol. 47, no. 1, pp. 234-41, Jan. 2013.

[15] C. M. Tenney and R. T. Cygan, "Molecular simulation of carbon dioxide, brine, and clay mineral interactions and determination of contact angles.," Environ. Sci. Technol., vol. 48, no. 3, pp. 2035-42, Feb. 2014.

[16] P. Chiquet, J.-L. Daridon, D. Broseta, and S. Thibeau, "CO2/water interfacial tensions under pressure and temperature conditions of $\mathrm{CO} 2$ geological storage," Energy Convers. Manag., vol. 48, no. 3, pp. 736-744, Mar. 2007.

[17] P. J. Miller and C. Van Atten, "North American Power Plant Emissions," 2004.

[18] V. Shah, D. Broseta, G. Mouronval, and F. Montel, "Water/acid gas interfacial tensions and their impact on acid gas geological storage," Int. J. Greenh. Gas Control, vol. 2, no. 4, pp. 594-604, Oct. 2008.

[19] S. Saraji, L. Goual, M. Piri, and H. Plancher, "Wettability of supercritical carbon dioxide/water/quartz systems: simultaneous measurement of contact angle and interfacial tension at reservoir conditions.," Langmuir, vol. 29, no. 23, pp. 6856-66, Jun. 2013.

[20] A. Kalantarian, R. David, and A. W. Neumann, "Methodology for high accuracy contact angle measurement.," Langmuir, vol. 25, no. 24, pp. 14146-54, Dec. 2009.

[21] P. K. Bikkina, "Contact angle measurements of $\mathrm{CO} 2-$ water-quartz/calcite systems in the perspective of carbon sequestration," Int. J. Greenh. Gas Control, vol. 5, no. 5, pp. 12591271, Sep. 2011. 
[22] P. K. Bikkina, "Reply to the comments on 'Contact angle measurements of CO2-waterquartz/calcite systems in the perspective of carbon sequestration," Int. J. Greenh. Gas Control, vol. 7, pp. 263-264, Mar. 2012.

[23] J. Mahadevan, "Comments on the paper titled 'Contact angle measurements of CO2water-quartz/calcite systems in the perspective of carbon sequestration': A case of contamination?," Int. J. Greenh. Gas Control, vol. 7, pp. 261-262, Mar. 2012.

[24] S. Iglauer, A. Salamah, M. Sarmadivaleh, K. Liu, and C. Phan, "Contamination of silica surfaces: Impact on water-CO2-quartz and glass contact angle measurements," Int. J. Greenh. Gas Control, vol. 22, pp. 325-328, Mar. 2014.

[25] R. K. Iler, The Chemistry of Silica: Solubility, Polymerization, Colloid and Surface Properties and Biochemistry of Silica, 1st ed. New York: John Wiley \& Sons, Inc., 1979, p. 866.

[26] E. F. Vansant, P. V. Der Voort, and K. C. Vrancken, Characterization and Chemical Modification of the Silica Surface, 1st ed. Amsterdam: Elsevier B.V, 1995, p. 556.

[27] R. G. Horn, D. T. Smith, and W. Haller, "Surface forces and viscosity of water measured between silica sheets," Chem. Phys. Lett., vol. 162, no. 4,5, 1989.

[28] A. Mennella and N. R. Morrow, "Point-by-point method of determining contact angles from dynamic Wilhelmy plate data for oil/brine/solid systems," J. Colloid Interface Sci., no. 172 , pp. 48-55, 1995.

[29] A. Siebold, M. Nardin, and J. Schultz, "Effect of dynamic contact angle on capillary rise phenomena," Colloids Surfaces A Physicochem. Eng. Asp., vol. 161, pp. 81-87, 2000.

[30] A. L. Sumner, E. J. Menke, Y. Dubowski, J. T. Newberg, R. M. Penner, J. C. Hemminger, L. M. Wingen, T. Brauer, and B. J. Finlayson-pitts, "The nature of water on surfaces of laboratory systems and implications for heterogeneous chemistry in the troposphere," Phys. Chem. Chem. Phys., no. 6, pp. 604-613, 2004.

[31] D. Koschel, J.-Y. Coxam, L. Rodier, and V. Majer, "Enthalpy and solubility data of CO2 in water and $\mathrm{NaCl}(\mathrm{aq})$ at conditions of interest for geological sequestration," Fluid Phase Equilib., vol. 247, no. 1-2, pp. 107-120, Sep. 2006.

[32] S. Bachu and D. B. Bennion, "Interfacial Tension between CO2, Freshwater, and Brine in the Range of Pressure from (2 to 27) $\mathrm{MPa}$, Temperature from (20 to 12 ) ${ }^{\circ} \mathrm{C}$, and Water Salinity from (0 to 334 000) mg L-1," J. Chem. Eng. Data, no. 54, pp. 765-775, 2009.

[33] T. L. Tarbuck and G. L. Richmond, "Adsorption and Reaction of CO2 and SO2 at a Water Surface,” J. Am. Chem. Soc., no. 128, pp. 3256-3267, 2006. 
[34] J. Mills, M. Riazi, and M. Sohrabi, "Wettability of common rock-forming minerals in a CO2-brine system at reservoir conditions," SCA2011-06, pp. 1-12, 2011.

[35] D. Yang, Y. Gu, and P. Tontiwachwuthikul, "Wettability determination of the reservoir brine - reservoir rock system with dissolution of $\mathrm{CO} 2$ at high pressures and elevated temperatures," Energy \& Fuels, no. 22, pp. 504-509, 2008.

[36] J. L. Dickson, G. Gupta, T. S. Horozov, B. P. Binks, and K. P. Johnston, "Wetting phenomena at the CO2/water/glass interface.," Langmuir, vol. 22, no. 5, pp. 2161-70, Feb. 2006.

[37] Y. Sutjiadi-Sia, P. Jaeger, and R. Eggers, "Interfacial tension of solid materials against dense carbon dioxide," J. Colloid Interface Sci., vol. 320, pp. 268-274, 2008. 
Table 1- Density, interfacial tension, and water advancing and receding contact angles of $\mathrm{CO}_{2} /$ brine/quartz systems measured in this study. (The reported errors in this table are the standard deviation of the mean value)

\begin{tabular}{|c|c|c|c|c|c|c|c|c|c|c|c|}
\hline Test & $\begin{array}{c}\mathbf{P} \\
\text { (psig) }\end{array}$ & $\begin{array}{c}\mathrm{T} \\
\left({ }^{0} \mathrm{C}\right)\end{array}$ & $\begin{array}{c}\text { Ionic } \\
\text { Strength } \\
\text { (M) }\end{array}$ & $\begin{array}{c}\mathrm{SO}_{2} \\
\text { (wt.\%) }\end{array}$ & $\begin{array}{c}\rho_{\mathrm{CO} 2} \\
\left(\mathrm{~kg} / \mathrm{m}^{3}\right)\end{array}$ & $\begin{array}{c}\rho_{\text {Brine }} \\
\left(\mathrm{kg} / \mathrm{m}^{3}\right)\end{array}$ & $\begin{array}{c}\Delta \rho \\
\left(\mathrm{kg} / \mathrm{m}^{3}\right)\end{array}$ & $\begin{array}{c}\text { IFT } \\
(\mathrm{mN} / \mathrm{m})\end{array}$ & $\begin{array}{l}\theta_{\mathrm{WR}} \\
\left({ }^{0}\right)\end{array}$ & $\begin{array}{r}\theta_{\mathrm{WA}} \\
\left({ }^{0}\right)\end{array}$ & $\begin{array}{l}\Delta \theta \\
\left({ }^{0}\right)\end{array}$ \\
\hline 1 & 2000 & 50 & 1 & 0 & 672 & 1040 & 369 & $31.4 \pm 0.1$ & $14.6 \pm 0.9$ & $25.9 \pm 0.9$ & $11.3 \pm 0.9$ \\
\hline 2 & 2000 & 60 & 1 & 0 & 561 & 1034 & 473 & $28.7 \pm 0.2$ & $13.6 \pm 1.0$ & $23.5 \pm 1.0$ & $9.9 \pm 1.0$ \\
\hline 3 & 3000 & 60 & 1 & 0 & 742 & 1036 & 294 & $28.7 \pm 0.1$ & $14.6 \pm 1.0$ & $29.3 \pm 0.5$ & $14.7 \pm 0.7$ \\
\hline 4 & 3000 & 70 & 1 & 0 & 687 & 1031 & 345 & $27.0 \pm 0.1$ & $11.6 \pm 0.7$ & $29.0 \pm 0.6$ & $17.4 \pm 0.6$ \\
\hline 5 & 3000 & 80 & 1 & 0 & 612 & 1024 & 412 & $25.0 \pm 0.4$ & $13.3 \pm 0.7$ & $25.4 \pm 1.8$ & $12.0 \pm 1.3$ \\
\hline 6 & 4000 & 70 & 1 & 0 & 771 & 1034 & 264 & $26.7 \pm 0.4$ & $12.1 \pm 0.5$ & $33.0 \pm 1.4$ & $20.9 \pm 0.9$ \\
\hline 7 & 4000 & 80 & 1 & 0 & 721 & 1028 & 307 & $27.9 \pm 0.1$ & $10.5 \pm 0.8$ & $27.1 \pm 0.7$ & $16.6 \pm 0.7$ \\
\hline 8 & 4000 & 90 & 1 & 0 & 679 & 1021 & 342 & $26.3 \pm 0.1$ & $11.5 \pm 0.7$ & $25.5 \pm 0.8$ & $14.0 \pm 0.7$ \\
\hline 9 & 4000 & 100 & 1 & 0 & 636 & 1012 & 377 & $28.6 \pm 0.2$ & $8.8 \pm 0.6$ & $27.0 \pm 0.2$ & $18.2 \pm 0.4$ \\
\hline 10 & 3000 & 60 & 0.2 & 0 & 740 & 1010 & 270 & $26.0 \pm 0.3$ & $10.0 \pm 0.2$ & $20.5 \pm 0.9$ & $10.5 \pm 0.5$ \\
\hline 11 & 3000 & 70 & 0.2 & 0 & 674 & 1003 & 329 & $23.9 \pm 0.2$ & $9.8 \pm 0.7$ & $16.5 \pm 1.0$ & $6.7 \pm 0.8$ \\
\hline 12 & 3000 & 80 & 0.2 & 0 & 614 & 996 & 382 & $23.6 \pm 0.2$ & $11.0 \pm 0.7$ & $17.0 \pm 1.9$ & $6.0 \pm 1.3$ \\
\hline 13 & 3000 & 60 & 5 & 0 & 739 & 1166 & 427 & $39.2 \pm 0.2$ & $17.3 \pm 0.9$ & $35.7 \pm 0.7$ & $18.4 \pm 0.8$ \\
\hline 14 & 3000 & 70 & 5 & 0 & 674 & 1162 & 488 & $39.2 \pm 0.7$ & $19.8 \pm 1.2$ & $44.1 \pm 1.5$ & $24.2 \pm 1.4$ \\
\hline 15 & 3000 & 80 & 5 & 0 & 613 & 1147 & 534 & $38.3 \pm 0.8$ & $20.0 \pm 1.4$ & $42.2 \pm 2.1$ & $22.2 \pm 1.7$ \\
\hline 16 & 3000 & 60 & 1 & 1 & 739 & 1022 & 283 & $27.0 \pm 0.4$ & $14.0 \pm 0.1$ & $27.0 \pm 0.2$ & $13.0 \pm 0.2$ \\
\hline 17 & 3000 & 60 & 1 & 6 & 778 & 1023 & 245 & $18.4 \pm 0.7$ & $12.9 \pm 1.0$ & $27.6 \pm 2.5$ & $14.7 \pm 1.7$ \\
\hline
\end{tabular}




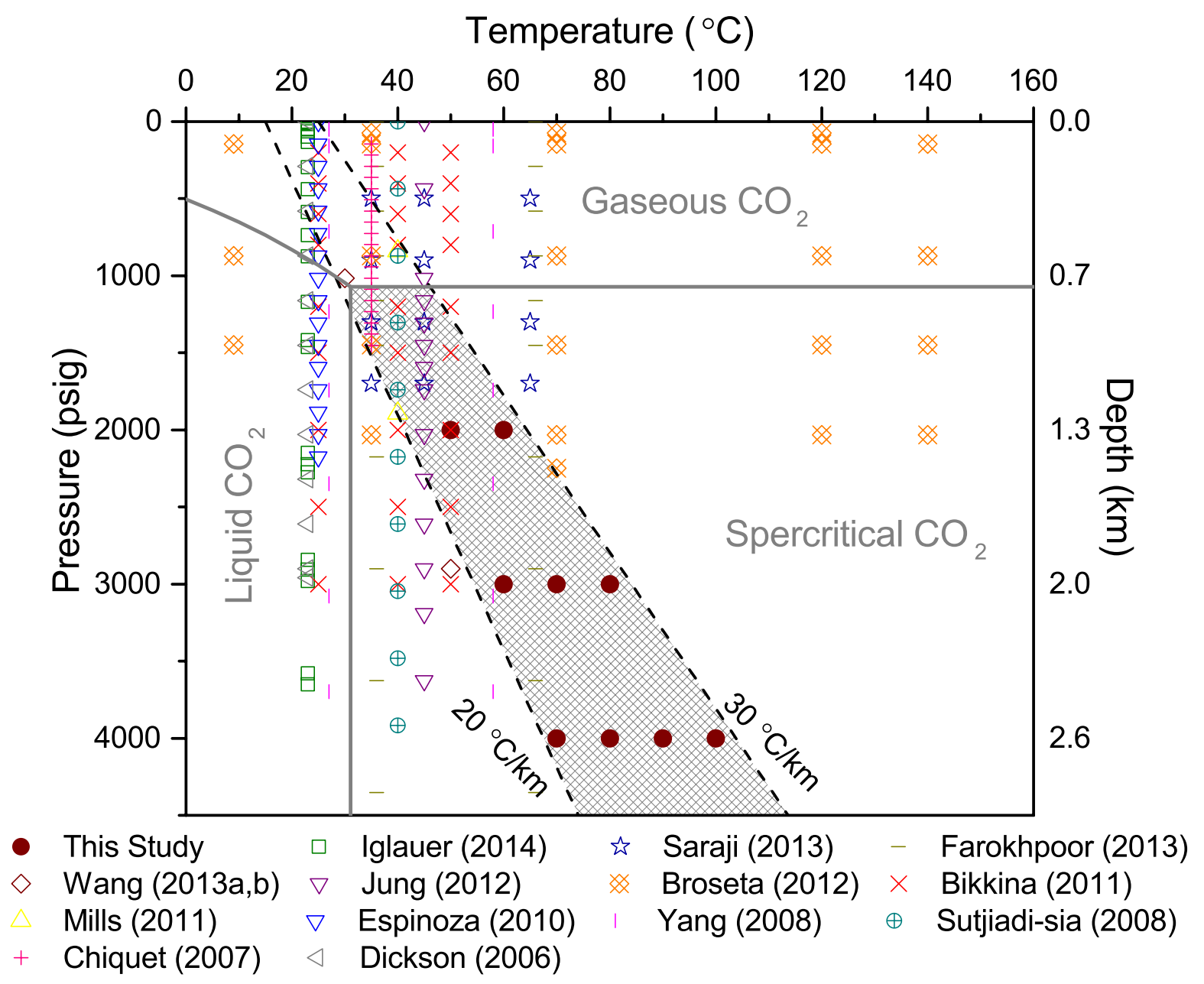

Figure 1- Pressure and temperature conditions used in this study and in the literature [5], [7]-[11], [14], [19], [21], [24], [34]-[37]. 


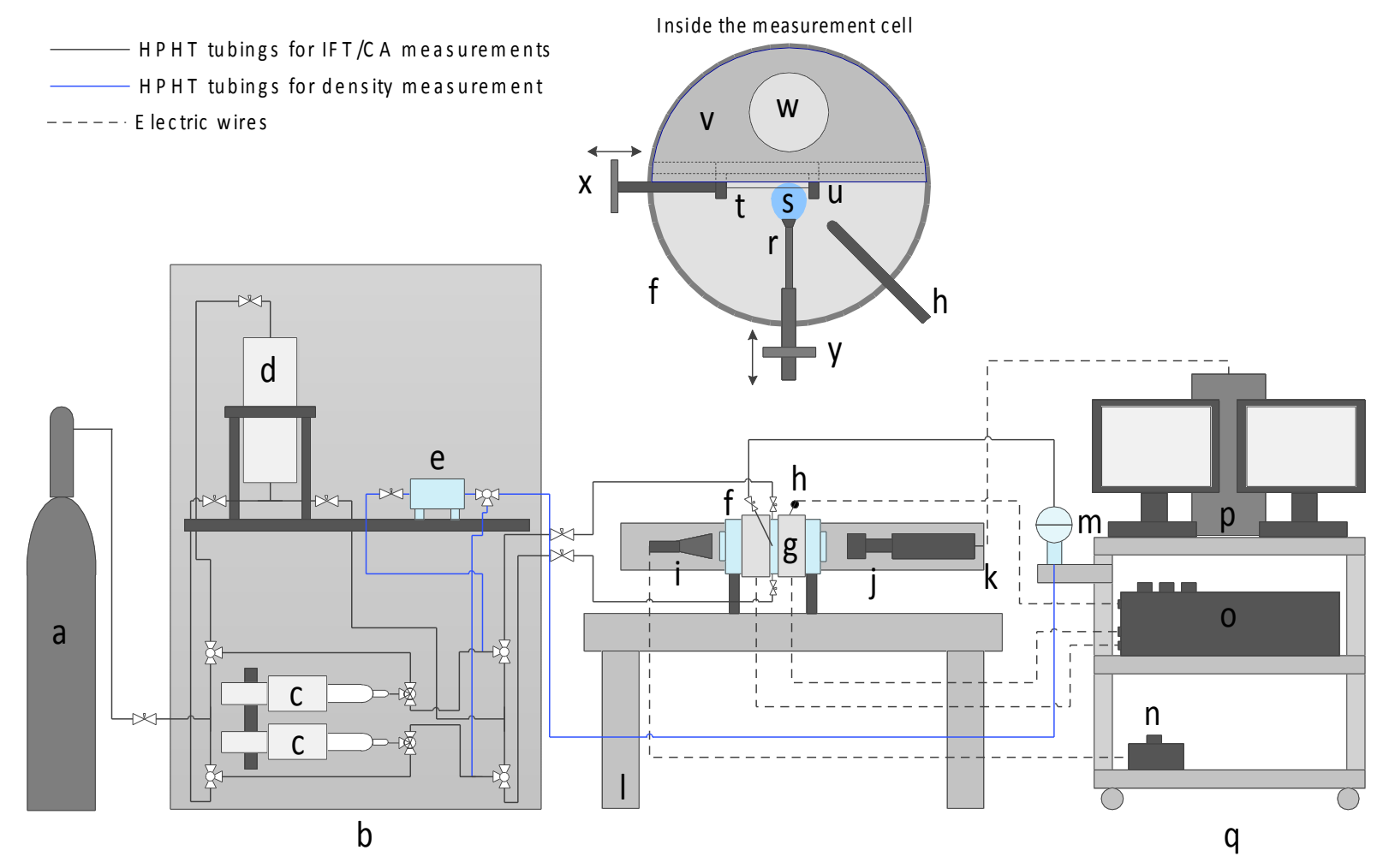

Figure 2- Schematic of the experimental setup used in this study; (a) $\mathrm{CO}_{2}$ cylinder, (b) mechanical convection oven, (c) dual-cylinder Quizix pump, (d) equilibration cell, (e) density meter, (f) measurement cell, (g) heating jackets, (h) RTD, (i) light source, (j) apochromaticallycorrected lenses and CCD camera, (k) adjustable stand, (l) anti-vibration table, (m) Rosemount pressure sensor, (n) current source, (o) temperature control system, (p) data acquisition computer, (q) shelf cart, (r) IFT/CA needle, (s) fluid bubble, (t) solid substrate, (u) movable tray, (v) crystal holder, (w) fluid level observation opening, (x) horizontal drive shaft, and (y) vertical drive shaft. 

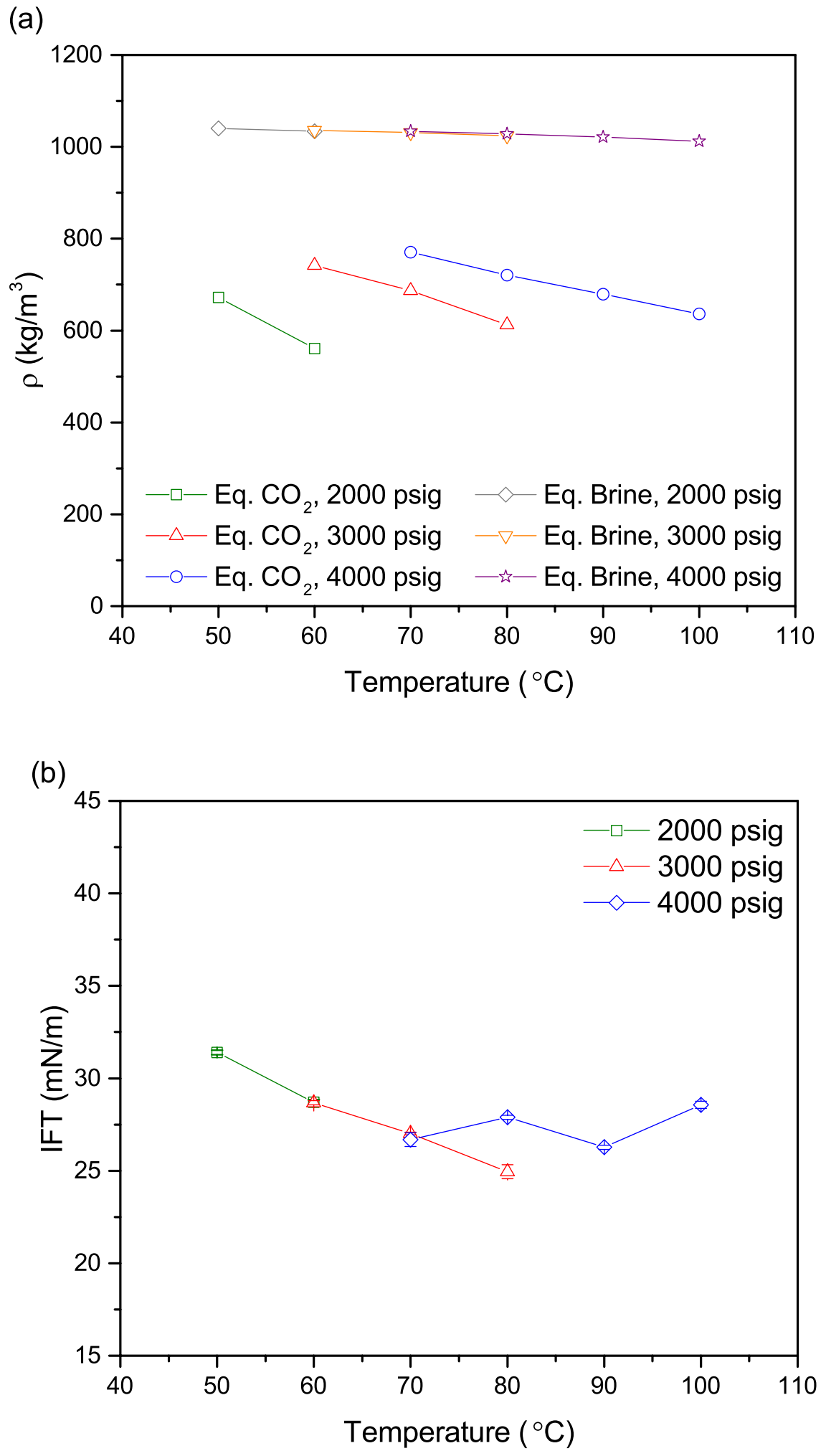

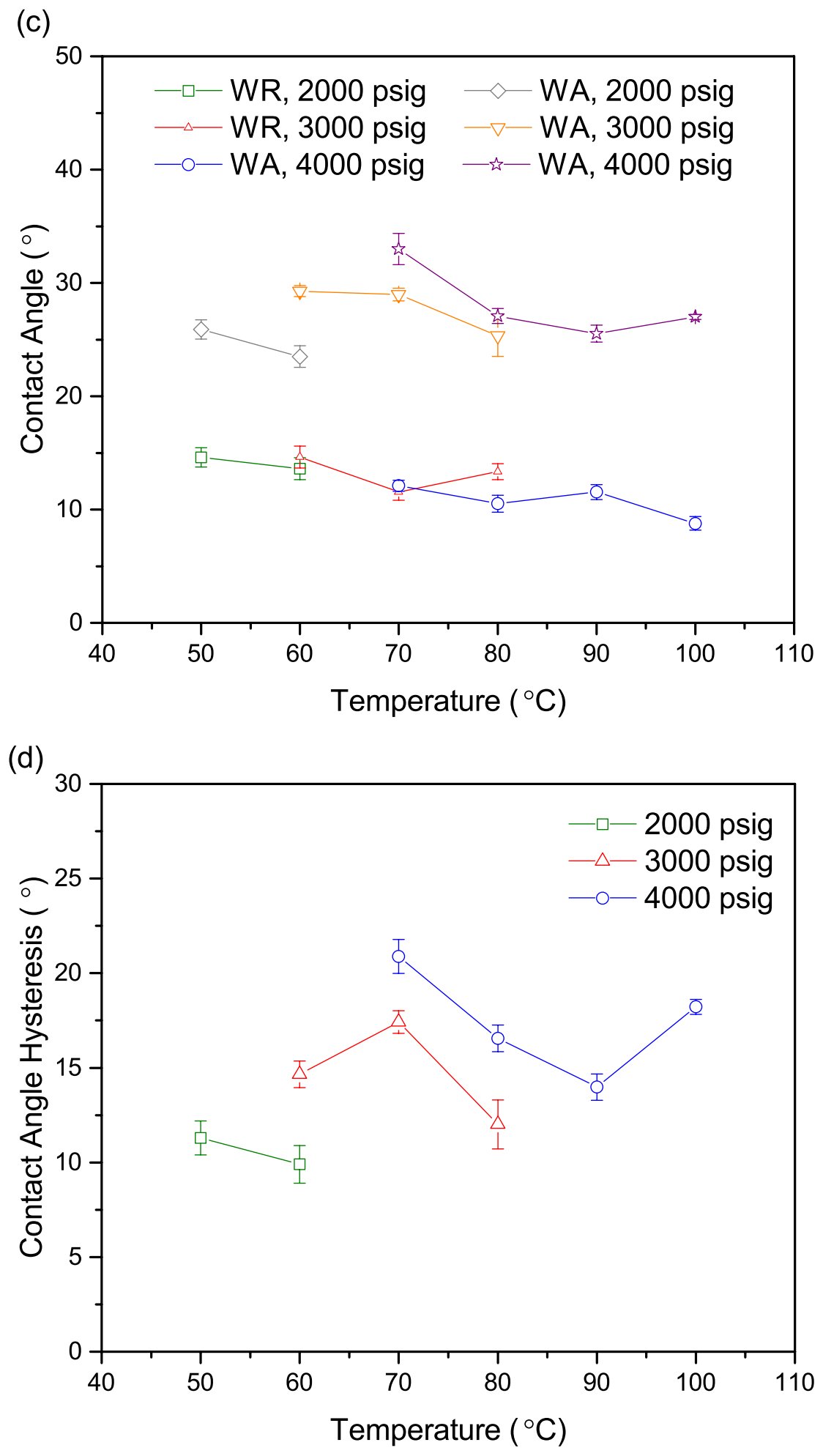

Figure 3- Effects of pressure and temperature on (a) density, (b) interfacial tension, (c) dynamic contact angles (WR: water receding, WA: water advancing), and (d) contact angle hysteresis $(\Delta \theta)$ of $\mathrm{CO}_{2} /$ brine/quartz system. 

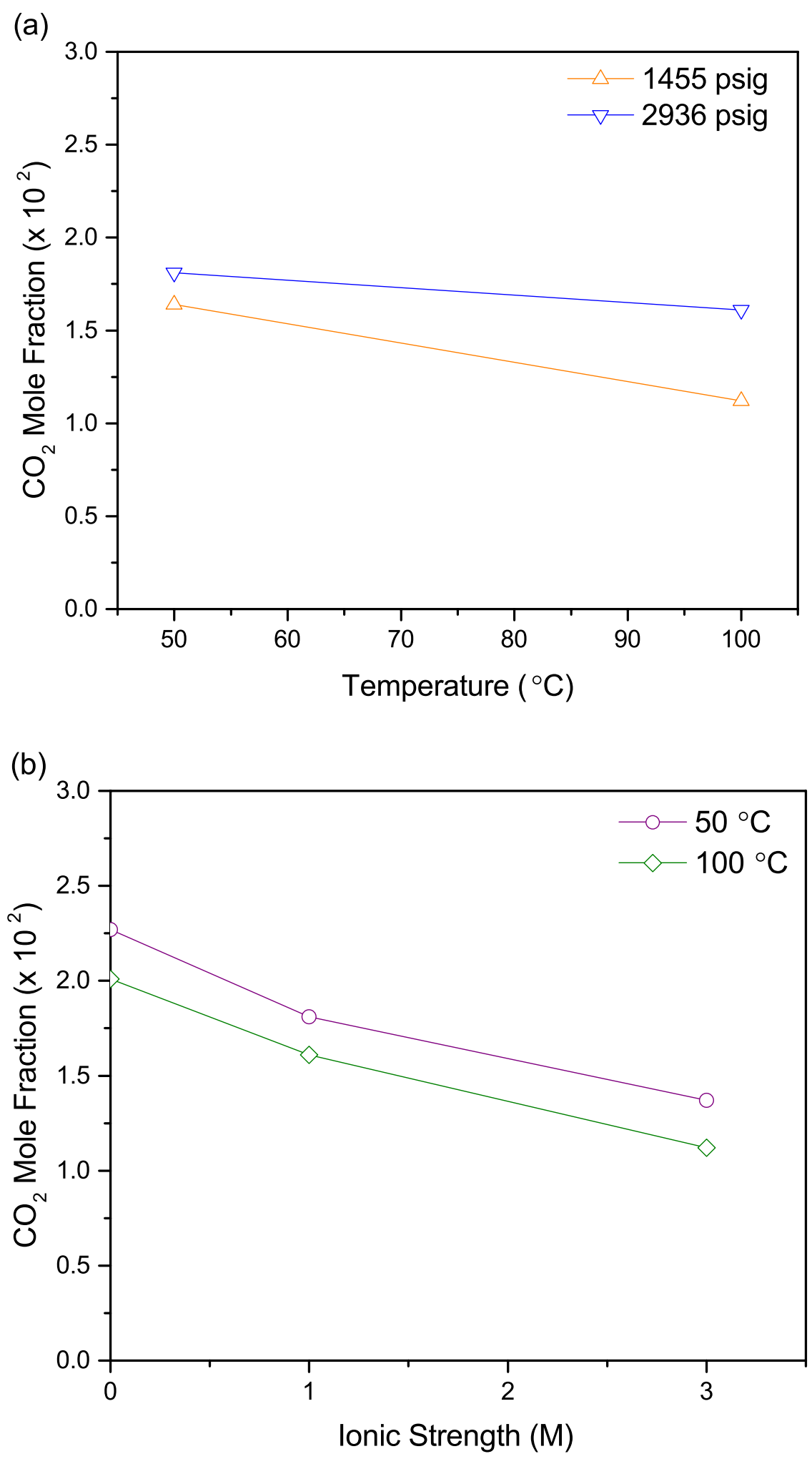

Figure 4- Variations in $\mathrm{CO}_{2}$ solubility in brine with (a) pressure and temperature ( $1 \mathrm{M}$ brine), and (b) brine salinity (at 3000 psig) (data from Koschel et al. [31]). 
(a)
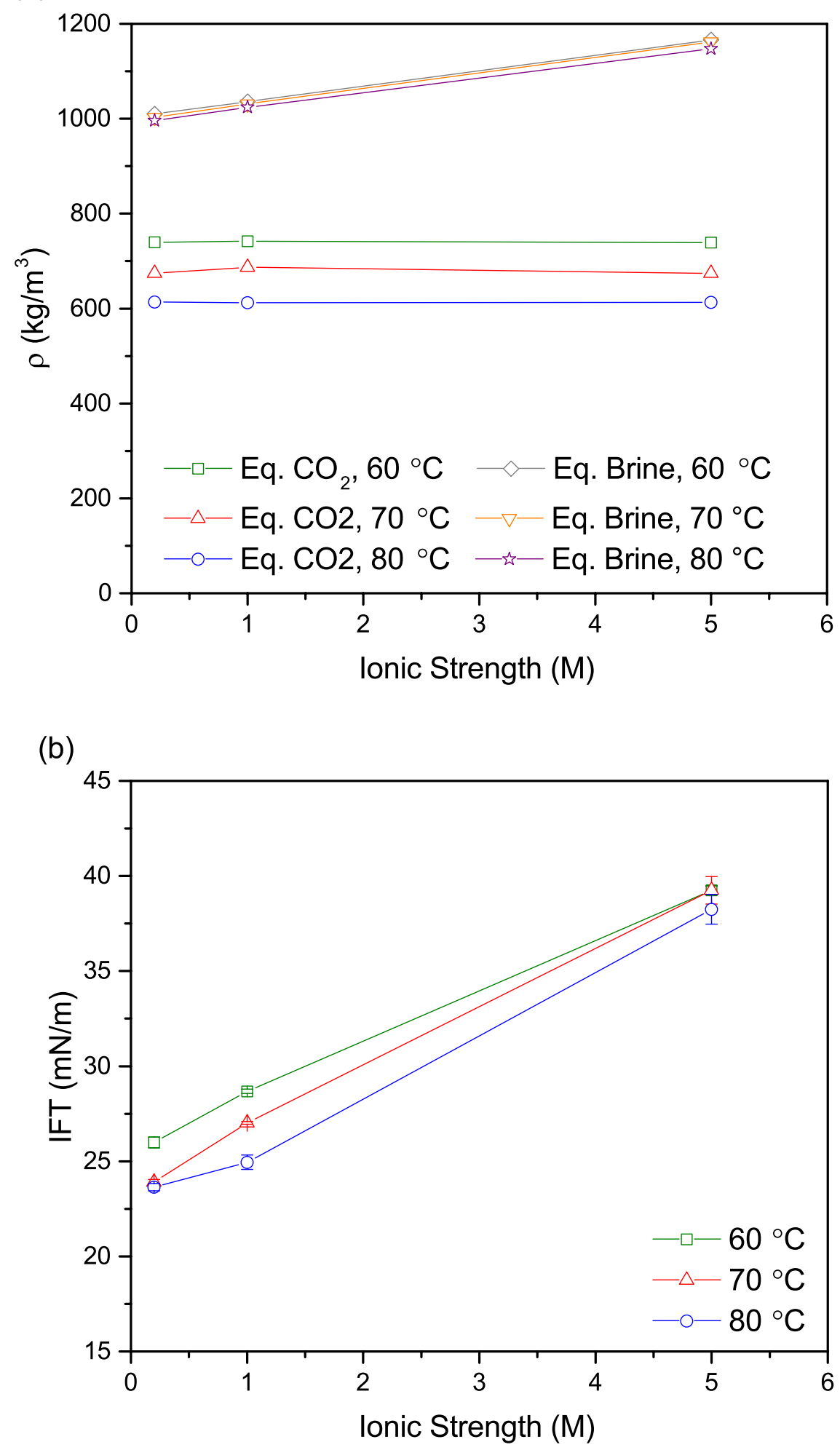

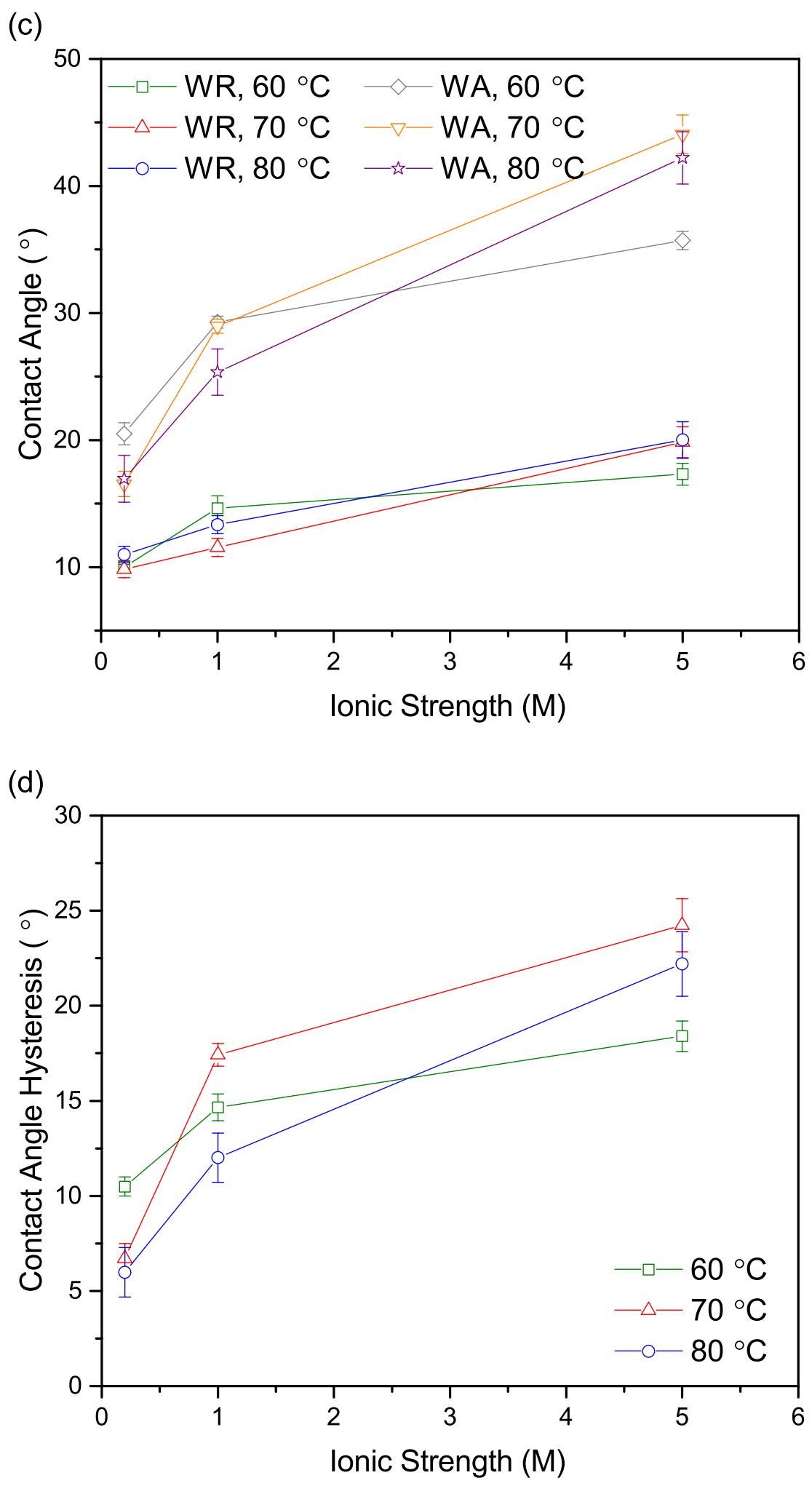

Figure 5- Effects of brine salinity on (a) density, (b) interfacial tension, (c) dynamic contact angles (WR: water receding, WA: water advancing) and (d) contact angle hysteresis $(\Delta \theta)$ of $\mathrm{CO}_{2}$ /brine/quartz system. (All the measurements were performed at $3000 \mathrm{psig}$ ) 
(a)

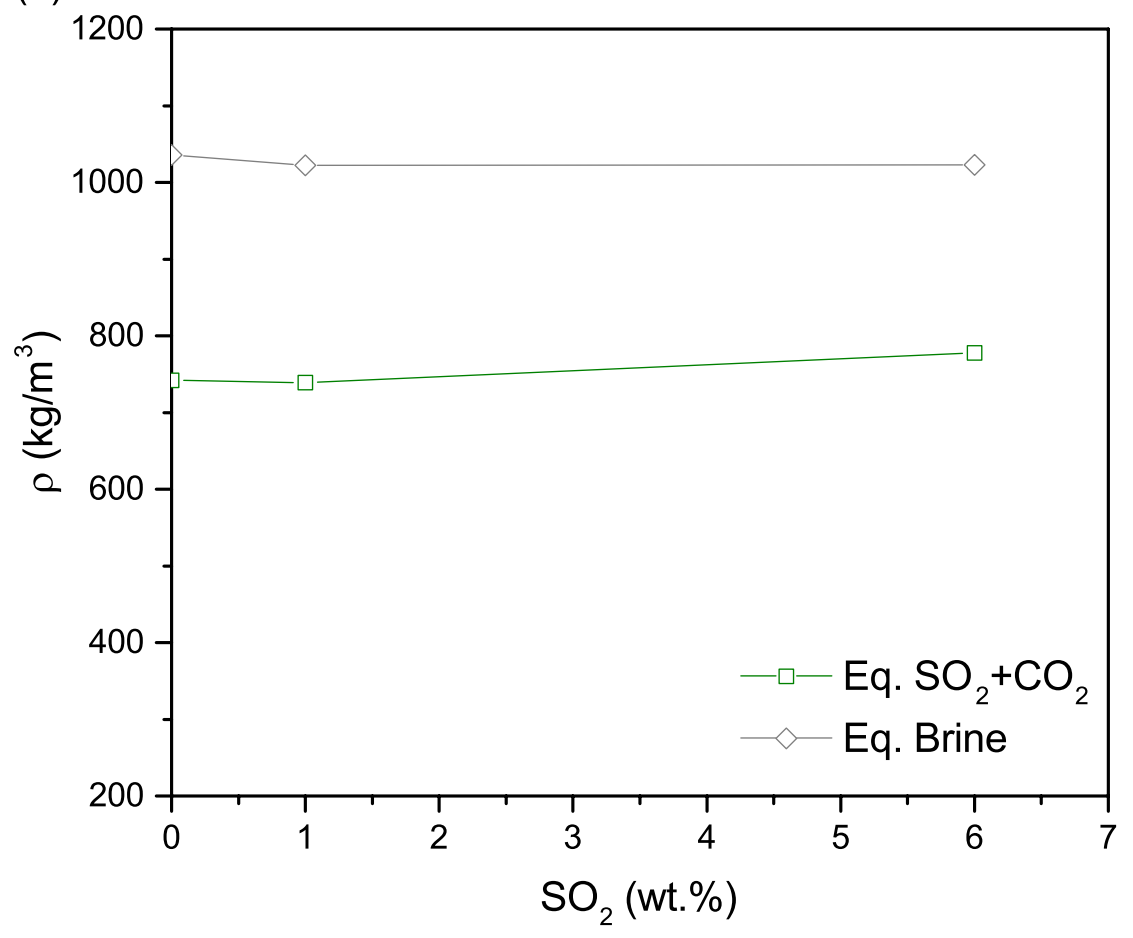

(b)

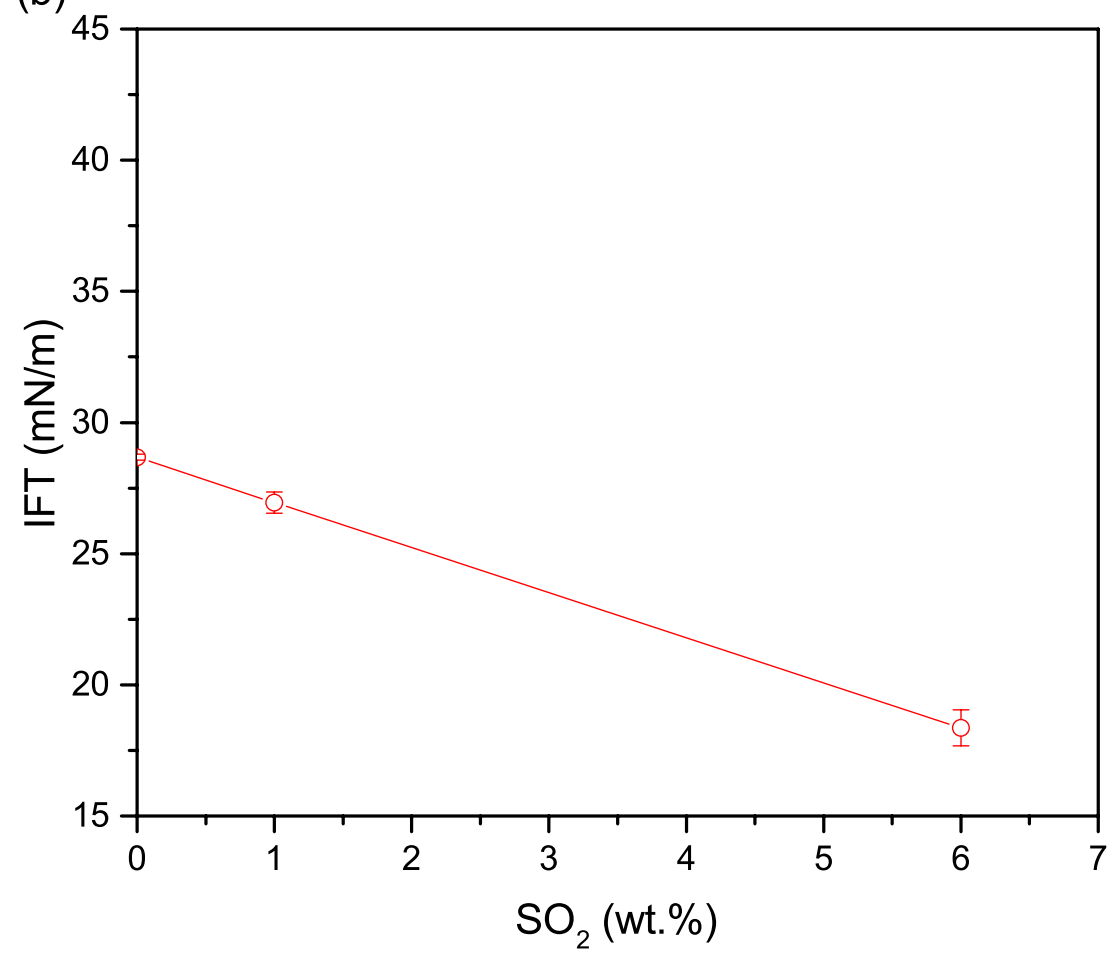



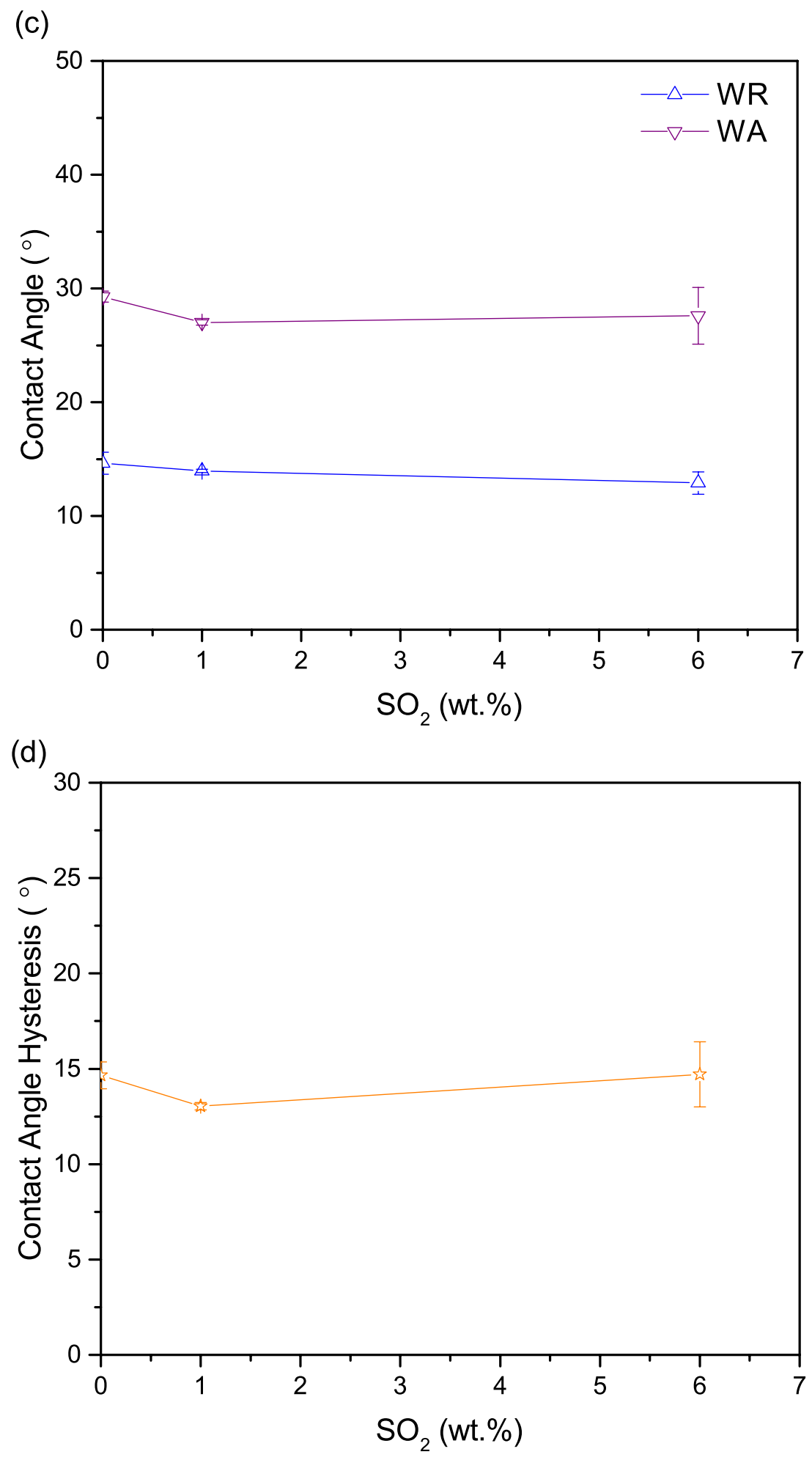

Figure 6- Effects of $\mathrm{SO}_{2}$ concentration on (a) density, (b) interfacial tension, (c) dynamic contact angles (WR: water receding, WA: water advancing) and $(\mathrm{d})$ contact angle hysteresis $(\Delta \theta)$ of $\mathrm{SO}_{2}+\mathrm{CO}_{2} /$ brine/quartz system. (All the measurements were performed at $3000 \mathrm{psig}, 60{ }^{\circ} \mathrm{C}$, and $1 \mathrm{M}$ brine salinity) 